\title{
Prevalence of Psychological Distress Among Quarantined People in the Trivandrum District During the COVID-19 Pandemic: A Cross-sectional Study
}

Sneha S Prakash, ${ }^{1}$ Sneha Sabu, ${ }^{1}$ Jayaprakash Raghavan,, ${ }^{2}$ Chintha Sujatha. ${ }^{3}$

\begin{abstract}
Background: Quarantine is considered the most effective way to reduce the transmission of an infectious disease. The outbreak of coronavirus disease-19 (COVID-19) in 2020 led to many people being quarantined at various locations. The literature shows that people who undergo quarantine face psychological problems, such as depression, anxiety and stress. The aim of this study was to estimate the prevalence of psychological issues among quarantined people during the COVID-19 pandemic. Methods: This cross-sectional study was conducted in Trivandrum, Kerala, India. Adults aged 18 years and above who underwent quarantine in the area of the Pangappara Medical Health Centre were included. A semi-structured questionnaire and the Depression Anxiety Stress Scale-21 were administered to those who had given their informed consent. Quantitative variables were summarized using mean, standard deviation, and categorical variables with proportions. Significance of association was tested using the chi-square tests. Results: There were 143 participants included in the study. It was found that $23.8 \%$ had depressive symptoms, $14 \%$ had anxiety symptoms and $16.8 \%$ had significant stress. People from the age group of 26-40 years $(p=0.017)$, people from the higher educated group $(p=0.010)$ and non-resident Keralites (Keralites who were residing elsewhere and returned to Kerala during the pandemic) $(p=0.041)$ had the highest prevalence of depressive symptoms. Conclusion: People who undergo quarantine face many psychological issues. The health care system should provide adequate psychosocial support to quarantined people suffering from psychological problems. Health care workers should undergo appropriate training to provide these supports.
\end{abstract}

Key Words: Coronavirus Disease; COVID-19; Quarantine; Depression; Anxiety; Stress (Source: MeSH-NLM).

\section{Introduction}

The coronavirus disease (COVID-19) pandemic that started in China was declared a public health emergency of international concern by the World Health Organization (WHO) on 30 January 2020. ${ }^{1}$ On 11 March 2020, it was subsequently declared a pandemic. ${ }^{2}$ The first case of COVID 19 in India was reported in the southern state of Kerala on $30^{\text {th }}$ January 2020.3 The number of cases has been increasing ever since. Transmission of infectious diseases is often controlled by quarantine and isolation of the population at risk. ${ }^{4}$

Quarantine is the separation and restriction of people who have potentially been exposed to a contagious disease to ascertain if they become unwell so as to reduce the risk of them infecting others. ${ }^{5}$ The term 'quarantine' was first used in Venice, Italy, in 1127 with regard to the spread of leprosy and was widely used during the period of the Black Death in England. ${ }^{6}$ In the case of the COVID-19 pandemic, the WHO issued quarantine guidelines on 29 February 2020.7 Previous studies have shown that implementing strict quarantine measures can precipitate various psychological problems, such as panic disorder, anxiety disorder and depression. ${ }^{8}$ Other negative psychological issues that may be triggered by quarantines include post-traumatic stress symptoms, confusion and anger. ${ }^{9} \mathrm{~A}$ study conducted among Chinese university students during the COVID-19 outbreak also reports that mandatory quarantine is significantly associated with emotional distress. ${ }^{10}$ According to Hawryluck et.al, symptoms of post-traumatic stress disorder and depression were observed in $28.9 \%$ and $31.2 \%$ of people quarantined during the Severe Acute Respiratory Syndrome (SARS) epidemic. ${ }^{11}$

Several studies have investigated the psychological impact of pandemics and the lockdown that follows on the general population, as well as among healthcare workers. ${ }^{2-21}$ The quarantined population differs from the general population in that they had to follow a strict protocol and stay in isolation due to the risk of probable exposure to the disease. According to the guidelines issued by the Ministry of Health and Family Welfare, Government of Kerala, the people coming from outside countries, from states outside Kerala, and those who had primary contact with people who tested positive for COVID-19 were required to spend 14 days at home or an institutional quarantine facility. ${ }^{22}$ There are only limited studies, especially in an Indian setting, investigating the extent and prevalence of psychological issues among those who were quarantined. These psychological issues include depression, anxiety and stress. Thus, this study aims to better understand these psychological issues and their relationship with factors such as age and educational status to help formulate better policies to improve population mental health during this period.

The primary objective of this study is to estimate the prevalence of psychological issues such as symptoms of depression, anxiety and stress among quarantined people in the Trivandrum district during the COVID-19 pandemic. The secondary objective is to assess associations of psychological issues during a quarantine with socio-demographic factors.

1 Undergraduate Medical Student, Government Medical College, Thiruvananthapuram, India.

DPM, M.D. Paediatrics, PhD. Child Psychiatry, Additional Professor and Child Psychiatrist, Department of Paediatrics, SAT Hospital, Government Medical College, Thiruvananthapuram, India.

3 M.D. Community Medicine, Associate Professor, Department of Community Medicine, Government Medical College, Thiruvananthapuram, India.

About the Author: Sneha S Prakash is currently a third-year medical student of Government Medical College, Thriuvananthapuram, India of a five-and-half years' program. She is also a recipient of National Talent Search Examination scholarship.

Correspondence:

Sneha S Prakash

Address: Government Medical College, Thiruvananthapuram, India Email: snehasp817@gmail.com
Editor: Francisco J. Bonilla-Escobar Student Editors: Adam Dinoff, Rahul Abraham 8 Abdul Basith K M Copyeditor: Leah Komer Proofreader: Sohaib Haseeb Layout Editor: Sushil Dahal
Submission: Jun 2, 2021 Revisions required: Jul 7, Sep 42021 Received in revised form: Aug 3, Sep 262021 Acceptance: Sep 20, 2021 Acceptance: sep 202 Publication: Sep 29, 2021 Process: Peer-reviewed 


\section{Methods}

A cross-sectional study was done in the area of Pangappara Medical Health Centre Unit, in the Trivandrum district, India. Trivandrum district is the capital city of Kerala, India with a mostly urban population.

The study population included all adults who had undergone quarantine in the Trivandrum district during the COVID-19 pandemic, were classified under the Pangappara Medical Health Centre Unit, could be contacted over the phone and consented to participate in the study. The data was collected between July 2020 and September 2020 through telephone interviews. The data was collected from individuals who had completed their quarantine in the past 7 days and had consented to participate in the study. The study was started only after obtaining permission and ethical approval from the health authorities and clearance from the Institutional Ethics Committee (HEC No. $03 / 51 / 2020 / \mathrm{MCT}$ ). The list containing the details of the people under quarantine in the district, under the Pangappara Medical Health Centre Unit, was obtained from the Administrative Medical Officer. Those quarantined individuals in the list who were aged 18 years and above and had given their informed consent constituted the study participants. These study participants were contacted over the phone and invited to participate in the study. The participants gave their informed consent after learning about the procedure and objectives of the study. They were assured that they would not have any financial burden due to participating in the study, that they could withdraw from it at any time they wanted and that none of their personal details would be published or misused in any way.

Inclusion criteria included all persons aged 18 years and above who had undergone quarantine in Trivandrum district during the COVID-19 pandemic.

The study tools used to measure psychological illness, sociodemographic factors and medical comorbidities included the Depression and Anxiety Stress Scale (DASS-21) ${ }^{23}$ as well as a semistructured questionnaire. The semi-structured questionnaire was used to collect relevant information regarding the socio-demographic factors as well as comorbidities. The socio-demographic factors investigated included variables such as age, sex, educational status, occupational status and resident status. Non-resident Keralites include Non-Resident Indians (NRIs) as well as Keralites who had been residing in other states and returned to Kerala during the time of the pandemic. Resident Keralites denote the native residents of Kerala and non-Keralites residing in Kerala refer to the natives of other states who were residing in Kerala during the pandemic period. The DASS-21 is a symptomanalysis scale and contains 21 questions, seven questions each for Depression, Anxiety and Stress. ${ }^{23}$ Each question is graded on a 4-point Likert scale and the scores range from 0 to 3 . To calculate the tota score for each condition, the scores of relevant questions were added together and the value obtained was multiplied by 2 as per the description in the tool manual. The scores obtained for each question in the DASS-21 questionnaire were added as per the guidelines given in the DASS score sheet to obtain the total scores for depression, anxiety and stress. ${ }^{23}$ The cut-off scores given in the tool manual to categorize as Depression, Anxiety and Stress were at 9, 7 and 14, respectively. This tool has been validated in the regional setting and used for other Indian studies. ${ }^{18}$

\section{Statistical Analysis and Sample Size Calculation:}

According to Hawryluck et al. the prevalence of post-traumatic stress disorder among quarantined people is $28.9 \% .{ }^{11}$ Using this value in the equation $3.84 * p q / d 2$, the sample size is calculated as (as suggested by a statistician): $p=29, q=71$, Absolute precision $d=25 \%$ of $p=8$. Sample size $=3.84 * p q / d 2=124$. Therefore, the target sample size was set at 130 to be conservative.

The sociodemographic data and the DASS-21 scores collected were entered in a Microsoft Excel spreadsheet and analyzed using Statistical
Package for Social Sciences (SPSS) Version 25.0 for Windows. Quantitative variables were summarized in means and standard deviations while categorical variables were summarized as proportions. Significance of association was tested using Chi-square tests ( $p<0.05)$.

\section{Results}

There were approximately 250 people in the list and 204 were over the age of 18 . Seventeen calls could not be connected because either the phones were switched off or they were out of network coverage area and 18 persons did not attend the call. Out of the remaining 169, 143 individuals gave consent to participate in the study.

The study population was composed of 143 adults, of which $96(67.1 \%)$ were males, and $47(32.9 \%)$ were females, with ages ranging from 18 to 72 , the mean age being 36.28 . The socio-demographic characteristics of the study population are shown in Table 1. The main sociodemographic characteristics that were assessed included gender, age, educational status, occupation and place of residence. All of the 143 adults included in the study were quarantined at their respective homes except one person, who was under institutional quarantine.

Nearly about one-fourth of the study population, 34 out of $143(23.8 \%)$ were found to have depressive symptoms; 20 out of $143(14 \%)$ were found to have symptoms of anxiety; and 24 out of $143(16.8 \%)$ were found to have symptoms of stress as per DASS-21. Associations of sociodemographic factors with depression, anxiety, and stress are shown in Table 2. Among these factors, age group (in years) $(p=0.017)$, education status $(p=0.010)$ and place of residence (i.e., Resident Status) $(p=0.041)$ showed statistically significant associations with depressive symptoms. None of the studied variables were significantly associated with anxiety symptoms. Only education status $(\mathrm{p}=0.005)$ was significantly associated with stress (Table 2)

Table 1. Socio-demographic characteristics of the study population $(n=143)$.

\begin{tabular}{lc}
\hline Socio-demographic Variables & Frequency $\mathbf{n}(\%)$ \\
Gender & $96(67.1)$ \\
Male & $47(32.9)$ \\
Female & \\
Age Groups (in years) & $24(16.8)$ \\
18-25 & $75(52.4)$ \\
$26-40$ & $42(29.4)$ \\
$41-65$ & $2(1.4)$ \\
$>65$ & \\
Education & $31(21.7)$ \\
Pre-degree and below & $112(78.3)$ \\
Degree and above & $103(72.0)$ \\
Occupation & $11(7.7)$ \\
Professionals and skilled workers & $12(8.4)$ \\
Unskilled workers & $17(11.9)$ \\
Students & $83(58.0)$ \\
None & $49(34.3)$ \\
Place of Residence (Resident Status) & $11(7.7)$ \\
Non-Resident Keralites & \\
Resident Keralites & \\
Non-Keralites residing in Kerala & \\
\hline
\end{tabular}

Legend: Non-resident Keralites include non-resident Indians (NRIs) as well as Keralites who had been residing in other states and returned to Kerala during the time of the pandemic, resident Keralites denote the native residents of Kerala and non-Keralites residing in Kerala refer to the natives of other states who were residing in Kerala during the pandemic period. The category 'Pre-degree and below' in education includes people who have received formal education only up to Grade 12 or below. The category 'degree and above' includes people who have completed formal school education and are either pursuing or have received a college degree. 


\section{Discussion}

Among the study population, it was found that $23.8 \%$ had depressive symptoms, $14 \%$ had anxiety symptoms and $16.8 \%$ symptoms of significant stress as per DASS-21. People aged 26 to 40 years had the highest prevalence of depressive symptoms, followed by the 18 to 25 years' age group. Regarding educational status, a higher proportion of people from the higher educated group were found to have depressive symptoms when compared with the group that had a lower educational status. Stress followed the same pattern of association and was significantly associated with higher educational status. Regarding resident status, a higher prevalence of depressive symptoms was found among Non-Resident Keralites.

In a study conducted in West Bengal, Chakraborthy et al. found that the prevalence of depression among the general population due to lockdown was $24.7 \% .^{12}$ Another study conducted in India found the prevalence of depression to be $25 \%$, anxiety $28 \%$ and stress $11.6 \%$ among the general population during the COVID-19 pandemic. ${ }^{18}$ Our study differs from those studies since they were conducted among the general public, while our study was specifically conducted among a group of people under quarantine. The quarantined population differs from the general population in that the quarantined population was more likely to be exposed to infection (in order to be forced to quarantine) and thus had to observe strict social distancing norms and other practices like handwashing and the use of face masks.

The findings obtained in our study correlate with many other studies which had revealed that pandemics put great pressure on the mental health of the general population. Many of these studies have used the same scale as we used (DASS-21). ${ }^{18}$ As stated earlier, Hawryluck et al. found similar findings among quarantined persons during the SARS epidemic. ${ }^{11}$ Another study conducted in Hong Kong among survivors of SARS found that $10 \%$ to $18 \%$ reported symptoms related to PTSD, anxiety and depression. ${ }^{24}$ In a study among the Ebola survivors and healthcare workers during the 2014-15 Ebola outbreak in Sierra Leone, the survivors had a higher prevalence of depression, anxiety and several other psychological disorders. ${ }^{25}$

The results obtained in the present study can be attributed to the quick spread of the pandemic across the world, which resulted in many people returning to their homes and native lands. Then, they found that they had to spend a certain number of days in quarantine and had to stay in their homes even after their quarantine periods were over. Moreover, most recreational activities such as traveling, meeting people and social gatherings were not possible. The importance of social groups in providing support has been studied in detail by groups such as Felton et.al. ${ }^{26}$ Moreover, while still in quarantine, people had to adjust to their 'new normal' way of life that included more video calls, online meetings, online classes and work-from-home. Above all, the fear of an unknown disease that was quickly spreading everywhere, the day by day increase in the number of cases and misinformation regarding various aspects of the disease could have contributed to the general increase in the prevalence of depression, anxiety, and stress among the quarantined population. Chakraborthy et al., in their study, had found that a significant proportion of the population was preoccupied with the idea of getting infected..$^{12}$ Some of the participants in our study also reported that they felt uncomfortable due to the social stigma attached to being in quarantine and that they had to face negative comments from their neighbors concerning this stigma.

The higher prevalence of depressive symptoms among the younger age groups in the present study may be because of the restrictions that the quarantine had imposed upon them, right in their prime productive age. This included restrictions on social mobility and their usual pursuits of recreation like meeting with their social circle and traveling.

Table 2. Associations of Socio-Demographic Factors with Depression, Anxiety, and Stress $(n=143)$.

\begin{tabular}{|c|c|c|c|c|c|c|}
\hline Socio-demographic Variables & $\begin{array}{c}\text { Depression Present } \\
\mathrm{n}(\%)\end{array}$ & $p$-value & $\begin{array}{c}\text { Anxiety Present } \\
n(\%)\end{array}$ & p-value & $\begin{array}{c}\text { Stress Present } \\
\mathrm{n}(\%)\end{array}$ & p-value \\
\hline \multicolumn{7}{|l|}{ Gender } \\
\hline Males & $22(22.9)$ & 0.73 & $12(12.5)$ & 0.464 & $16(16.7)$ & 0.957 \\
\hline Females & $12(25.5)$ & & $8(17.0)$ & & $8(17.0)$ & \\
\hline \multicolumn{7}{|l|}{ Age Groups (in years) } \\
\hline $18-25$ & $7(29.2)$ & 0.017 & $5(20.8)$ & 0.369 & $6(25.0)$ & 0.071 \\
\hline $26-40$ & $24(32.0)$ & & $12(16.0)$ & & $16(21.3)$ & \\
\hline $41-65$ & $3(7.1)$ & & $3(7.1)$ & & $2(4.8)$ & \\
\hline$>65$ & $0(0)$ & & $0(0)$ & & $0(0)$ & \\
\hline \multicolumn{7}{|l|}{ Education } \\
\hline Predegree and below & $2(6.5)$ & 0.01 & $2(6.5)$ & 0.172 & $0(0.0)$ & 0.005 \\
\hline Degree and above & $32(28.6)$ & & $18(16.1)$ & & $24(21.4)$ & \\
\hline \multicolumn{7}{|l|}{ Occupation } \\
\hline Professionals and skilled workers & $25(24.3)$ & 0.051 & $14(13.6)$ & 0.18 & $17(16.5)$ & 0.205 \\
\hline Unskilled workers & $2(18.2)$ & & $1(9.1)$ & & $0(0.0)$ & \\
\hline Students & $6(50.0)$ & & $4(33.3)$ & & $4(33.3)$ & \\
\hline None (Unemployed) & $1(5.9)$ & & $1(5.9)$ & & $3(17.6)$ & \\
\hline \multicolumn{7}{|l|}{ Place of residence (Resident Status) } \\
\hline Non-resident Keralites & $26(31.3)$ & 0.041 & $14(16.9)$ & 0.503 & $19(22.9)$ & 0.051 \\
\hline Resident Keralites & $6(12.2)$ & & $5(10.2)$ & & $5(10.2)$ & \\
\hline Non-Keralites residing in Kerala & $2(18.2)$ & & $1(9.1)$ & & $0(0.0)$ & \\
\hline
\end{tabular}

Legend: Non-resident Keralites include non-resident Indians (NRIS) as well as Keralites who had been residing in other states and returned to Kerala during the time of the pandemic. Resident Keralites denote the native residents of Kerala and non-Keralites residing in Kerala refer to the natives of other states who were residing in Kerala during the pandemic period.

The category Predegree and below in education includes people who have received formal education only up to Class 12 of school or below. The category Degree and above includes people who have completed formal school education and are either pursuing or have received a college degree. 
Another study also reported that younger age groups, especially the 18 24 years' age group and the $25-35$ years' age group, had a more negative psychological impact when compared with the rest of the population. In comparison, the ones above 65 years of age had the least psychological impact. ${ }^{14}$ Moreover, most of these participants were home-quarantined and had a fear of infecting family members who might be more vulnerable. Many people, especially those belonging to the 26 to 40 years' age group, had worries regarding the safety of their families, especially their elderly parents and young children. In support of this finding, a study conducted in Wuhan by Zhu et al. reported that living with family and worries about family members getting infected were risk factors for psychological problems among healthcare workers during the beginning of the COVID-19 pandemic. ${ }^{20}$

This study also found that a higher proportion of people among the group with higher education had depressive symptoms and stress. This could be because they were more aware of the risks and chances of contracting the infection. They were possibly also more aware of the ongoing research on the long-term complications that might arise due to COVID-19; hence, they had more worry than their counterparts from the group that had less education. On the other hand, the participants were not being diagnosed by a healthcare provider but were answering questions over the phone. Therefore, perhaps, people with lower education status were more prone to reporting bias or there may have been a knowledge gap, which led to this finding.

The higher prevalence of depressive symptoms among Non-Resident Keralites could be attributed to their worries regarding the loss of their jobs and livelihood, fear of infecting their family members, the difficulties of getting accustomed to work-from-home, and other such concepts. Some of the study participants also reported that they were sad that they could not see their family and friends from their

\section{References}

1. World Health Organization. WHO Director-General's statement on IHR Emergency Committee on Novel Coronavirus (2019-nCoV). Available from: https://www.who.int/director-general/speeches/detail/who-director-general-sstatement-on-ihr-emergency-committee-on-novel-coronavirus-(2019-ncov). Cited Jan 21, 2021.

2. World Health Organization. WHO Director-General's opening remarks at the media briefing on COVID-19. 11 March 2020. Available from: https://www.who.int/director-general/speeches/detail/who-director-general-sopening-remarks-at-the-media-briefing-on-covid-19. Last update: Mar-11,-2020; cited Jan 21, 2021

3. Department of Health and Family Welfare, Government of Kerala. COVID-19 Dashboard. Available from: https://covid19.kerala.gov.in/dboard.php. Cited Nov 27, 2020.

4. Hossain MM, Sultana A, Purohit N. Mental health outcomes of quarantine and isolation for infection prevention: A systematic umbrella review of the global evidence. Epidemiol Health. 2020 March 17.

5. Centers for Disease Control and Prevention. Quarantine and Isolation. Available from: https://www.cdc.gov/quarantine/index.html. Cited Jan 30, 2020.

6. Newman K. Shutt Up: Bubonic plague and quarantine in early modern England. J Sol Hist. 2012 February 06;45(3):809-834.

7. World Health Organization. Considerations for quarantine of individuals in the context of containment for coronavirus disease (COVID-19) : interim guidance, 29 February 2020.2 Available from: https://apps.who.int/iris/handle/10665/331299. Cited Jan 21, 2021.

8. Qiu J, Shen B, Zhao M, Wang Z, Xie B, Xu Y. A nationwide survey of psychological distress among Chinese people in the COVID-19 epidemic: Implications and policy recommendations. Gen Psychiatr. 2020 March 06;33(2):1-3. hometowns. However, they understood the reason and necessity of the quarantine process. This could also have contributed to a higher prevalence of depressive symptoms among this group.

A limitation of this study was that it was conducted by interviewing the study participants over the phone, which might not yield results with the same accuracy as self-reporting or a face-to-face interview. Other limitations such as selection bias, interviewer bias and report bias may also have affected the outcome of the study. In addition, as this was a cross-sectional study, we can only infer correlation and not causation from these results, and a clear conclusion cannot be clearly stated because of the possibility of confounders altering the levels of psychological distress in the study population.

\section{Conclusion}

The present study has concluded that a considerable group of people who had undergone quarantine faced psychological problems like depressive symptoms, anxiety symptoms and stress. This issue needs to be addressed since it demonstrates that the mental health of quarantined individuals can differ from the general population based on unique challenges and may need to be approached from a different perspective. This can be done by reaching out to these individuals and providing adequate psychological support and counseling services. Moreover, primary healthcare workers should be trained to identify and address the mental health issues of quarantined people and offer necessary support and services. The services that have already been launched by the Government of Kerala to provide mental health support such as telecounselling services namely, "Ottakkalla Oppamund" (translated as "You're not alone, we are with you"), need to be strengthened. As the authors, we feel that family members and the general public should be made aware of the psychological impacts of quarantine and they could benefit from their constant love and support.
9. Brooks SK, Webster RK, Smith LE, Woodland L, Wessely S, Greenberg N, et. al. The psychological impact of quarantine and how to reduce it: Rapid review of the evidence. The Lancet. 2020 March 14-20;395(10227):912-920.

10. Xin M, Luo $S$, She $R$, Yu Y, Li L, Wang $S$, et. al. Negative Cognitive and Psychological Correlates of Mandatory Quarantine During the Initial COVID-19 Outbreak in China. American Psychologist. 2020;75(5):607-617.

11. Hawryluck L, Gold WL, Robinson S, Pogorski S, Galea S, Styra R. SARS Control and Psychological Effects of Quarantine, Toronto, Canada. Emerging Infected Dis. 2004 July; 10(7):1206-1212.

12. Chakraborthy K, Chatterjee M. Psychological impact of COVID-19 pandemic on general population in West Bengal: A cross-sectional study. Indian J Psychiatry 2020 May 15;62(3):266-72.

13. Grover S, Sahoo S, Mehra A, Avasthi A, Tripathi A, Subramanyan A et. al. Psychological impact of COVID-19 lockdown: An online survey from India. Indian J Psychiatry. 2020 July 27;62(4):354-362.

14. Rodriguez-Rey, Garrido-Hernansaiz H, Collado S. Psychological Impact and Associated Factors During the Initial Stage of the Coronavirus (COVID-19) Pandemic Among the General Population in Spain. Front. Psychol. 2020 June 23;11:1540.

15. Salari N, Hosseinian-Far A, Jalali R, Vaisi-Raygani A, Rasoulpoor S, Mohammad $M$, et. al. Prevalence of stress, anxiety, depression among the general population during the COVID-19 pandemic: A systematic review and meta-analysis. Global Health. 2020 July $06 ; 16(1): 57$.

16. Shah SMA, Mohammad D, Qureshi MFH, Abbas MZ, Aleem S. Prevalence, Psychological Responses and Associated Correlates of Depression, Anxiety and Stress in a Global Population, During the Coronavirus Disease (COVID-19) Pandemic. Community Ment Health J. 2021 Jan;57(1):101-110.

17. Wang C, Pan R, Wan X, Tan Y, Xu L, Ho CS, et. al. Immediate Psychological Responses and Associated Factors during the Initial Stage of the 2019 
Coronavirus Disease (COVID-19) Epidemic among the General Population in China. Int J Environ Res Public Health. 2020 March 06;17(5):1729.

18. Verma S, Mishra A. Depression, anxiety and stress and socio-demographic correlates among general Indian public during COVID-19. International Journal of Social Psychiatry. 2020 June 20;66(8):756-762.

19. Wilson W, Raj JP, Rao S, Ghiya M, Nedungalaparambil NM, Mundra H, et. al. Prevalence and Predictors of stress, anxiety and Depression among Healthcare Workers Managing COVID-19 Pandemic in India: A Nationwide Observational Study. Indian Journal of Psychological Medicine. 2020 July 06;42(4):353-358.

20. Zhu Z, Xu S, Wang H, Liu Z, Wu J, Li G, et. al. COVID-19 in Wuhan: Sociodemographic characteristics and hospital support measures associated with the immediate psychological impact on healthcare workers. EClinicalMedicine. 2020 July;24:100443.

21. Mohindra $R, R$ R, Suri $V$, Bhalla $A$, Singh SM. Issues relevant to mental health promotion in frontline health care providers managing quarantined/isolated COVID-19 patients. Asian J Psychiatr. 2020 June; 51:102084.

22. Health and Family Welfare Department, Government of Kerala. Revised Guidelines for testing, quarantine, hospital admission and discharge for COVID-
19 based on current risk assessment. 12-03-2020 Available from: https://dhs.kerala.gov.in/wp-content/uploads/2020/03/reg_12032020.pdf. Cited Jan 21, 2021.

23. Lovibond PF, Lovibond SH. The structure of negative emotional states: Comparison of the Depression Anxiety Stress Scales (DASS) with the Beck Depression and Anxiety Inventories. Behav Res Ther. 1995 March;33(3):335-343.

24. Wu KK, Chan SK, Ma TM. Posttraumatic stress, anxiety and depression in survivors of severe acute respiratory distress syndrome (SARS). J Trauma Stress. 2005 February; 18(1):39-42.

25. Ji D, Ji YJ, Duan X, et. al. Prevalence of psychological symptoms among Ebola survivors and healthcare workers during the 2014-2015 Ebola outbreak in Sierra Leone: A cross-sectional study. Oncotarget. 2017 February 21;8(8):12784-12791.

26. Felton B], Berry C. Groups as social network members: overlooked sources of social support. Am J Community Psychol. 1992 April;20(2):253-61.

\section{Acknowledgments}

Dr Sharija S, Additional Professor, Department of Forensic Medicine, Government Medical College, Thriuvananthapuram.

\section{Conflict of Interest Statement at Funding}

The Authors have no funding, financial relationships or conflicts of interest to disclose.

\section{Author Contributions}

Conceptualization, Methodology, Project Administration, Visualization: SSP, SS, RJ, CS; Data Curation, Formal Analysis, Investigation, Writing-Original Draft Preparation: SSP, SS; Resources, Software, Supervision, Validation, Writing-Review and Editing: RJ, CS.

\section{Cite as}

Prakash SS, Sabu S, Raghavan J, Sujatha C. Prevalence of Psychological Distress Among Quarantined People in Trivandrum District During the CoVID-19 Pandemic: A Cross-sectional Study. Int J Med Students. 2021 Oct-Dec;9(4):269-73.

This work is licensed under a Creative Commons Attribution 4.0 International License

ISSN 2076-6327

This journal is published by the University Library System, University of Pittsburgh as part of the Digital Publishing Program and is co-sponsored by the University of Pittsburgh Press. 